\title{
A interferência do governo federal no gerenciamento de universidades privadas
}

Fernando Neri Sizílio

Universidade Estadual de Campinas

Sebastião A . R. Cerqueira

Universidade Estadual de Campinas

e-mail: cerqueira@mailcity.com.br

\section{Resumo}

Este artigo apresenta a Lei de Diretrizes e Bases da Educação Brasileira e como o Governo Federal interfere no gerenciamento de universidades privadas, principalmente no que diz respeito ao processo de tomada de decisão destas universidades.

\section{Palavras chaves}

LDB; Ensino superior privado; Gerenciamento de universidades.

\begin{abstract}
This article present the Law of Lines and Bases of the Brazilian Education and as the Federal Government interviews in the management of private universities, mainly in the making decision process of these universities.
\end{abstract}

\section{Key-words}

LDB; Private higher education; Management of university. 


\section{INTRODUÇÃO}

Este artigo tem como objetivo caracterizar a interferência do governo federal no gerenciamento de universidades particulares.

O tema aqui proposto vem sendo discutido há muito tempo nas universidades públicas em função da necessidade que estas instituições têm de demonstrarem eficácia e eficiência em suas ações.

Porém, pouco se verificou cientificamente quais as tendências organizacionais das universidades particulares, e como estas instituições têm se articulado com o Governo Federal. As universidade particulares sempre foram apontadas como instituições de ensino com plena liberdade de se organizarem em termos acadêmicos e administrativos. Este artigo vem demostrar que esta liberdade na realidade não existe e que a universidade particular, da mesma forma que a universidade pública, está sujeita a uma série de legislação que muitas vezes a coloca em uma "camisa de força" limitando, e muito, suas ações.

As organizações de um modo geral estão percebendo, através de constantes avaliações, a necessidade de agir de modo diferente para sobreviverem. Mesmo as organizações de sucesso, estão constantemente buscando novos padrões de comportamento com o objetivo de melhoria, senão, de consolidação e garantia de sua posição no ramo de atuação ao qual pertencem.

Observa-se que os administradores contemporâneos, seguindo essa tendência, buscam cultivar organizações saudáveis, objetivando uma resistência a longo prazo e não apenas resultados imediatos e de curto prazo.

A capacidade de reagir com rapidez e precisão, adaptando-se agilmente às mudanças, passa a ser o diferencial entre aquelas organizações que sobreviverão e as que sucumbirão diante das novas atitudes reclamadas e exigidas pelo mundo globalizado.

\section{A LEI DE DIRETRIZES E BASES EDUCAÇÃO E AS INSTITUIÇÕES PRIVADAS DE ENSINO SUPERIOR}

A interferência do Governo se faz mais evidente na criação da Universidade de Brasília e na própria sanção da Lei de Diretrizes e Bases da Educação Nacional. Certamente, não se pode negar, que o Governo Federal foi levado a tais atitudes em decorrência da forte pressão exercida pela sociedade por uma expansão do ensino superior.

Não é demais afirmar, como assim o fez o Padre José de Vasconcellos, presidente da Associação de Educação Católica do Brasil, que a lei de diretrizes e bases, "representou, por anos a fio, uma grande esperança para os educadores. A longa e laboriosa tramitação no Congresso Nacional, as discussões apaixonadas que suscitou deram ainda maior relevo a este sentimento comum" (VASCONCELLOS, 1968 : p.5).

Sobre essa pressão popular, escreveu CUNHA (1989 : p.109) que às "forças sociais, políticas e econômicas que determinaram a expansão, a integração e até mesmo a modernização do ensino superior se opuseram às forças defensoras do estado de coisas reinantes, em particular, do ensino elitista e arcaico" e 
completa o mesmo autor que, o "efeito contraditório dessas forças fez com que no mesmo ano em que era criada a Universidade de Brasília, promessa de significativa expansão de vagas e renovação dos métodos de ensino $e$ pesquisa, fosse promulgada a lei de diretrizes e bases da educação nacional, reforçando uma concepção oposta de ensino, principalmente no grau superior".

Ainda, havia as fortes manifestações populares pela obrigação e dever do Estado quanto ao ensino público.

O motivo de maior oposição dos defensores do ensino público e gratuito, estava estampado no Título III da Lei de Diretrizes e Bases da Educação Nacional, que tratava "Da Liberdade do Ensino" $e$, sobre o assunto, CUNHA (op. cit., p. 132) escreveu que a nova Lei "legitimava as principais reivindicações dos interesses privativistas, denominados interesses da 'liberdade do ensino', objeto, aliás, de todo um título do texto legal".

Naquela oportunidade, sobre esse particular, também manifestou a respeito, o presidente da União Nacional dos Estudantes, dizendo não poder "esconder sua decepção diante do sancionamento da atual Lei de Diretrizes e Bases, ainda privativista no seu estilo e forma, e por isso lesiva aos interesses populares que só poderão ser atendidos pela Escola Pública, gratuita e democrática..." (UNE, 1962; p.11).

De outro lado, entusiastas da nova Lei de Diretrizes e Bases da Educação se manifestavam, como, por exemplo, o professor Newton Sucupira. Segundo NISKIER (1995) para estes entusiastas os pontos básicos e inspiradores da Lei consistia "no princípio da autonomia da escola, ou seja, o poder de se organizar e dirigir suas atividades segundo normas por ela própria elaboradas", acrescentando ainda que, os pessimistas alegavam que o "excesso de liberdade pode tornar ainda mais mercantil o ensino privado, pois o professor não resistiria à pressão do diretor inconsciente que o obrigasse a fazer passar determinado aluno, mesmo que não tivesse condições para tal. Isso é raciocinar pelas possíveis exceções à regra. Na verdade, a análise da Lei de Diretrizes e Bases revela mais aspectos positivos do que negativos.

$O$ incentivo a um ensino mais flexível, a fim de se tornar mais eficiente; a melhor noção de equivalência dos cursos; a determinação de elevar o padrão universitário; a flexibilidade curricular, além dos fatores mencionados anteriormente - tudo isso resultou numa grande transformação de mentalidade na educação brasileira". (NISKIER, 1995; p.334).

De fato e de direito, entretanto, a sociedade brasileira a partir de então passou a conviver com o novo diploma legal, a despeito dos pensamentos e manifestações contrárias ou favoráveis de uns ou de outros segmentos.

A lei sancionada destacava, através de um tratamento diferenciado, as universidades e os estabelecimentos isolados de ensino superior. É claro na letra legal que, quando estabelece determinações para todo $\mathrm{o}$ sistema, nomeia-o de ensino superior, diferenciando das instituições isoladas de ensino superior, quando assim textualmente se refere. Há também, os ditames que se destinam a todo o sistema educacional do país. 
Determinado esse padrão, é possível discorrer brevemente sobre a Lei, obedecendo a um caminho que vai da norma geral para a norma específica do ensino superior, objetivando com isso ir aclarando o papel do Governo Federal e o que representou a própria legislação naquele contexto. Por outro lado, o detalhamento servirá de referencial para os estudos seguintes, com a vigência de outras leis que vierem em conflito ou complemento.

A Lei de Diretrizes e Bases da Educação Nacional tinha seus objetivos estampados logo no início, em seu Artigo $1^{\underline{o}}$, quais sejam: " a) a compreensão dos direitos $e$ deveres da pessoa humana, do cidadão, do Estado, da família e dos demais grupos que compõem a comunidade; b) o respeito à dignidade e às liberdades fundamentais do homem; c) o fortalecimento da unidade nacional e da solidariedade internacional; d) o desenvolvimento integral $\mathrm{da}$ personalidade humana e sua participação na obra do bem comum; e) o preparo do indivíduo e da sociedade para o domínio dos recursos científicos e tecnológicos que lhes permitam utilizar as possibilidades $e$ vencer as dificuldades do meio; f) a preservação e expansão do patrimônio cultural; g) a condenação a qualquer tratamento desigual por motivo de convicção filosófica, política ou religiosa, bem como a quaisquer preconceitos de classe ou de raça".

Essa visão humanística trazida pela Lei vinha justamente contrapor à visão socialista, que entendia a educação mais como um instrumento do Estado para a transformação do homem, colocando-o a serviço da sociedade. Os legisladores da LDB contribuíram, com a inserção desses princípios, de forma inequívoca para uma percepção mais adequada e humana da educação.

Para CUNHA (1989) o novo diploma legal legitimava as principais reivindicações dos interesses privativistas, denominados interesses da "liberdade do ensino", sendo objeto, aliás, de todo um título da Lei. É o que consta do Título III, artigos $4^{\circ}$ e $5^{\circ}$ da Lei.

O Art. $4^{\circ}$ assegura a "todos, na forma da lei, o direito de transmitir seus conhecimentos" e Art. $5^{\circ}$, assegura a todos os estabelecimentos de ensino, sejam eles públicos ou privados, a representação nos conselhos de educação do estado e reconhecimento dos estudos neles realizados.

Em verdade, o que pareceu causar maior impacto foi a equiparação do ensino privado ao ensino público e gratuito. Ao ensino privado foi impingida a pecha de mercantilista, como se esse fosse um grande defeito que tornasse o ensino das instituições privadas como impróprio. Certo também, que na oportunidade havia um agravante representado pela enorme quantidade de jovens aptos a ingressarem no ensino superior que não dispunha de muitas vagas, por deficiência do sistema. Muitos estudantes não tinham condições financeiras de assumir os encargos do ensino pago. Parecia haver uma certa indignação pela falta de criação de oportunidades pelo poder público.

Quanto às preocupações privativistas não havia razão bastante para fazer prosperar um movimento de maiores proporções, eis que a oportunidade da iniciativa privada na atividade de ensino, já havia sido tratada anteriormente, desde 11 de abril 1931, 
através do Decreto $\mathrm{n}^{\mathrm{o}} 19.851$ - Estatuto das Universidades Brasileiras, onde já estava evidente e pacífica a universidade particular.

Pela LDB de 1961, o Conselho Federal de Educação passa a ter um grande poder controlador, dependendo somente de homologação do Ministro da Educação para legitimação de seus atos.

$\mathrm{Na}$ forma estabelecida pelo Art. 9으, o Conselho Federal de Educação (CFE) passa a decidir sobre o funcionamento dos estabelecimentos isolados de ensino superior, sejam eles oficiais ou particulares. As universidades passam a depender do seu reconhecimento a partir da aprovação dos seus estatutos, o mesmo acontecendo com os estabelecimentos isolados de ensino superior, que poderiam ser reconhecidos somente após dois anos de funcionamento regular.

$\mathrm{O}$ poder do $\mathrm{CFE}$ permite intervenção em qualquer universidade ou instituição isolada de ensino superior, oficial ou particular, inclusive nomeando reitor temporário, chamando para si próprio as atribuições relativas aos Conselhos Universitários (Art. 84). Também ficaram sob a determinação do CFE a duração e o currículo mínimo obrigatório dos cursos superiores (Art. 9º alínea "e") sendo o assunto objeto de outras considerações mais adiante, quando é tratado o Art. 70.

Especificamente quanto aos objetivos do ensino superior, declarou a Lei em seu Art. 66, que o "ensino superior tem por objetivo a pesquisa, o desenvolvimento das ciências, letras e artes, e a formação de profissionais de nível universitário", firmando a seguir a validade em todo o território nacional dos diplomas expedidos pelas universidades ou pelas instituições isoladas, oficiais ou reconhecidas.

Quanto à estrutura do ensino superior, a previsão legal era que o ensino superior deveria ser ministrado em estabelecimentos agrupados ou não em universidades, com o apoio de institutos de pesquisa e centros de treinamento profissional.

A Lei parece que por extrema cautela do legislador, faz até um extenso detalhamento sobre o campo de atuação do ensino superior, quando declara no Art. 69 os cursos que lhe são de competência, como sendo de graduação (alínea "a"), para aqueles candidatos que houvessem concluído o ensino médio (segundo grau) e aprovados nos exames de vestibular e, de pós-graduação (alínea "b"), evidentemente, para os que concluíssem a graduação. Nesse detalhamento de competência, é relevante o dispositivo constante da alínea "c" seguinte, onde o legislador deixa de ser específico e passa a permitir que as instituições de ensino superior ministrem cursos de "especialização, aperfeiçoamento e extensão, ou quaisquer outros a juízo do respectivo instituto de ensino, abertos a candidatos com o preparo e os requisitos que vierem a ser exigidos".

O acesso ao ensino superior seria através dos concursos de habilitação (vestibular) e nesses poderiam se inscrever todos que concluíssem quaisquer cursos de nível médio (segundo grau) sem quaisquer preferências de formação para quaisquer dos cursos superiores. 
No Art. 70 é estabelecido que o currículo mínimo e a duração dos cursos serão fixados pelo Conselho Federal de Educação. Aqui vale o registro do comportamento do Governo Federal quando do veto ao parágrafo único. Dizia aquele parágrafo vetado que a "modificação do currículo ou da duração de qualquer desses cursos em um ou mais estabelecimentos integrantes de uma universidade, depende da aprovação prévia do mesmo conselho, que terá a faculdade de revogá-la se os resultados obtidos não se mostrarem vantajosos para o ensino". Vetando em todos os termos, manifestou-se o Governo Federal nas razões do veto que, o caput do Art. 70 já exigia "currículo mínimo e anos previstos de duração fixados pelo Conselho Federal de Educação para os cursos cuja diplomação assegure privilégios, o que constitui o máximo de regulamentação admissível em face da autonomia universitária. Pelo parágrafo único as exigências atingem a extremos ao impor autorização prévia do mesmo Conselho para qualquer modificação no currículo ou na modificação dos cursos. A experiência brasileira indica que nada ganhamos com a regulamentação rígida do ensino superior até agora vigente, pois nela só obtivemos um rigorismo formal no atendimento das exigências da lei em que nada contribui para a elevação dos padrões de ensino e para sua adaptação às condições locais" (VASCONCELLOs, 1968: p.15). Há aqui, inegavelmente, uma expressa preocupação do Governo Federal em promover uma maior flexibilização do sistema de ensino superior.

Nesta mesma linha de flexibilidade foram os vetos apostos pelo Governo Federal e mais tarde rejeitados pelo Congresso Nacional, que era pertinente aos Capítulos
II e III do Título IX que tratava Das Universidades e Dos Estabelecimentos Isolados de Ensino Superior.

As universidades seriam integradas por cinco ou mais instituições de ensino, não existindo a obrigatoriedade da integração através da faculdade de filosofia ciências e letras, nem que entre as instituições componentes da universidade tivessem, pelo menos, duas entre as faculdades de engenharia, de medicina ou de direito. A dispensa de obrigatoriedade das faculdades de filosofia, de ciências e de letras, foi decorrente do veto presidencial, sob o arrazoado de que já tínhamos no país mais de 70 faculdades de filosofia, que exerciam, ressalvadas as exceções, somente a função de formar professores para o grau médio, além do que, a integração esperada poderia ser exercida pelos institutos de pesquisas.

A autonomia universitária vinha declarada no Art. 80 como sendo didática, administrativa, financeira e disciplinar, exercida na forma de seus próprios estatutos. A seguir, os parágrafos primeiro, segundo e terceiro, declaravam em que consistiam as faculdades de autonomia didática, administrativa e financeira. Também aqui, nas razões do veto presidencial (embora rejeitado posteriormente, permanecendo todos os parágrafos), é possível se identificar o posicionamento do Governo Federal, ao declarar que a autonomia das universidades estava consagrada no caput do Art. 80, sendo desnecessário, via dispositivo de lei, regulamentar matéria que bem poderia ser comportada nos estatutos das próprias universidades, considerando que esses mesmos estatutos dependiam de aprovação do Conselho Federal de Educação. As razões do veto 
diziam ainda que os parágrafos vetados nada acrescentavam que representasse para o poder público a "garantia de responsabilidade que deve corresponder à autonomia, nem conferindo às universidades, qualquer regalia nova", acrescentando ainda que, ao "contrário, entra por vezes desnecessariamente, a estabelecer regras rígidas em assuntos que podem receber melhor tratamento, seja nos estatutos, seja nas normas que compete ao Conselho Federal de Educação estabelecer" (VASCONCELLOS, 1968: p.20).

Logo em seguida, o Art. 80 estabelecia a forma de constituição das universidades, podendo as oficiais ser constituídas sob a forma de autarquias ou de fundações e as particulares sob a forma de fundações ou de associações.

A gratuidade no ensino público superior, decorrente do Art. 168, Inciso II da Constituição então vigente, foi regulada no Art. 83.

A Lei remetia aos conselhos estaduais de educação o grau de recurso no caso dos estabelecimentos isolados de ensino superior estadual e municipal e, ao Conselho Federal de Educação, nos casos dos estabelecimentos federais ou particulares (Art. 87).

Quanto às instituições de ensino superior existentes na data da publicação da Lei de Diretrizes e Bases da Educação Nacional, o Art. 112 estabelecia um prazo de 180 dias para adaptação dos estatutos.

A Lei trouxe também em seu bojo conseqüências inesperadas tanto pelo Governo Federal como para as instituições de ensino superior e que, evidentemente, não poderiam ser previstas. Decorrente das seqüelas sociais é possível afirmar que um dos efeitos nefastos da Lei foi aquilo que resultou do disposto no Art. 78.

Através do indigitado dispositivo legal (Art. 78), a Lei $n^{0} 4.024 / 61$ reconhecia o direito de participação do corpo docente do governo das universidades e instituições isoladas de ensino superior, integrando seus conselhos universitários, congregações e conselhos departamentais, na forma estabelecida em seus respectivos estatutos. "Os estudantes temiam que as instituições de ensino redigissem estatutos onde sua participação fosse a menor possível, se não limitada a certas questões" (CUNHA, 1989: p.138). Os estudantes, organizados sob o manto da União Nacional dos Estudantes -UNE, se insurgiram e deflagraram manifestações de protestos por todo o país, culminando com uma greve de quase três meses, naquela que foi considerada a mais longa greve de estudantes no Brasil. Foram realizadas inúmeras assembléias, seminários e manifestos sobre a reforma universitária.

Também parece relevante para o estudo sendo objeto de futura análise, para verificação do papel atualmente desempenhado pelo Governo Federal e pela legislação vigente, o dispositivo da Lei $\mathrm{n}^{\mathrm{o}}$ 4.024/61 que vem estampado no Art. 114, que trata da transferência de entidade mantenedora das instituições de ensino superior e da destinação de seu patrimônio.

É possível perceber que a LDB/61 disposta de forma lógica e com boa técnica legislativa, disciplinou pontos importantes do ensino superior, tanto que, o que se 
seguiu a partir daí usou com freqüência o referencial nela contido.

Em 1996, surgiram também outros dispositivos, aos quais estão sujeitas as instituições privadas de ensino superior, sendo relevantes à presente pesquisa, estes serão aqui estudados, decorrentes ou não da atual Lei Diretrizes e Bases da Educação Nacional.

Depois de oito anos de discussões no Congresso Nacional, o Presidente da República Fernando Henrique Cardoso sancionou no dia 20 de dezembro de 1996, sem vetos, a Lei $\mathrm{n}^{\mathrm{o}}$ 9.394/96, sendo publicada no Diário Oficial da União no dia 23 de dezembro daquele mesmo ano, passando a determinar as diretrizes e bases da educação nacional.

As diretrizes da educação superior vêm na nova lei no Título V - Dos Níveis e das Modalidades de Educação e Ensino, Capítulo IV - Da Educação Superior, que é constituído pelos artigos de n ${ }^{\mathrm{os}} 43$ a 57 . Quando comparado com as seções que tratam da educação infantil, do ensino fundamental e médio, é possível perceber que há nesse capítulo da educação superior uma preocupação especial do legislador. Nota-se que foram traçadas linhas gerais para os outros níveis, havendo um maior detalhamento para o ensino superior. São quinze artigos, quinze parágrafos e trinta e sete incisos.

Segundo MOTTA (1997), este detalhamento se justifica porque a principal ação direta do Governo Federal, na área educacional, se dá no nível superior, já que aos municípios couberam maiores responsabilidades para com a educação infantil e o ensino fundamental e aos estados mais responsabilidades com o ensino médio e grande parte do ensino fundamental.

O novo dispositivo legal, considerado flexível e descentralizador, passou a fortalecer os sistemas estaduais de educação e trouxe uma série de inovações pedagógicas, entre as quais é possível citar, no que respeita ao ensino superior, a possibilidade de criação das Universidades especializadas por campo do saber, os novos modelos seletivos, a diplomação em cursos regulares através do ensino à distância, os novos parâmetros de titulação do corpo docente, a alternativa representada pelos Centros Universitários e pelos Institutos Superiores do Magistério, além da criação do processo nacional de avaliação das instituições de educação superior.

Embora o Capítulo tenha início com o Art. 43 , vale trazer primeiramente o texto do Art. 52 que estabelece a conceituação de universidade, e distinguindo-a das demais instituições isoladas de ensino superior, diz que se trata de instituições pluridisciplinares de formação dos quadros profissionais de nível superior, de pesquisa, de extensão e de domínio e cultivo do saber humano, que se caracterizam por: "I - produção intelectual institucionalizada mediante o estudo sistemático dos temas e problemas mais relevantes, tanto do ponto de vista científico e cultural, quanto regional $e$ nacional; II - um terço do corpo docente, pelo menos, com titulação acadêmica de mestrado ou doutorado; III - um terço do corpo docente em regime de tempo integral." O parágrafo único, faculta a criação de universidades especializadas por campo do saber. 
O disposto nos incisos II e III deste Art. 52, necessariamente deve ser estudado em conjunto com o parágrafo segundo do Art. 88 das Disposições Transitórias da mesma LDB, que estabelece um prazo de oito anos para o seu cumprimento pelas universidades. Segundo MOTTA (1997), as universidades com o objetivo de atingir ou até superar os níveis exigidos e de incentivar o aperfeiçoamento do corpo docente estão oferecendo valores mensais, adicionais aos valores pagos pelo trabalho, pela participação em programas de mestrados e doutorados. Outras estão firmando convênios com instituições nacionais e internacionais e financiam a participação dos seus docentes nestes programas.

O já citado parágrafo único do Art. 52 estabelece a possibilidade das universidades especializadas por campo do saber, o que constitui mais uma importante inovação da atual LDB frente à legislação anterior e que decorre da evolução do conceito de universidade. Parece que, diante do crescente volume de conhecimento, tornou-se quase impossível, dentro de uma única instituição, reunir todas as áreas de conhecimento, proporcionando excelência em todas elas. Por outro lado, mais vale uma universidade especializada em uma terminada área do saber, com excelentes níveis de qualidade naquilo que se propõe, do que uma enorme infra-estrutura que abranja variadas áreas e não consiga manter padrões recomendáveis de qualidade.

Na seqüência, o Art. 53 trata da autonomia das universidades, assegurando atribuições, sem prejuízo de outras que não são apresentadas, que lhes garantem a liberdade de ação, o que é apresentando com riqueza de detalhes em alguns aspectos que parecem fundamentais: " $I$ criar, organizar e extinguir, em sua sede, cursos e programas de educação superior previstos nesta lei, obedecendo às normas gerais da União e, quando for o caso, do respectivo sistema de ensino; II - fixar os currículos dos seus cursos e programas, observadas as diretrizes gerais pertinentes; III - estabelecer planos, programas e projetos de pesquisa científica, produção artística e atividades de extensão; IV - fixar o número de vagas de acordo com a capacidade institucional $e$ as exigências do seu meio; V-elaborar e reformar seus estatutos e regimentos em consonância com as normas gerais atinentes; VI - conferir graus, diplomas e outros títulos; VII - firmar contratos, acordos e convênios; VIII - aprovar e executar os planos, programas e projetos de investimentos referentes a obras, serviços e aquisições em geral, bem como administrar rendimentos conforme dispositivos institucionais; IX administrar os rendimentos e deles dispor na forma prevista no ato de constituição, nas leis e nos respectivos estatutos; $X-$ receber subvenções, doações, heranças, legados e cooperação financeira resultante de convênios com entidades públicas e privadas".

Quanto à autonomia didático-científica, diz a lei que os colegiados de ensino e pesquisa das universidades decidirão dentro dos recursos orçamentários disponíveis: "I - criação, expansão, modificação e extinção dos cursos; II ampliação e diminuição de vagas; III elaboração da programação dos cursos; IV - programação das pesquisas e das atividades de extensão; $V$ - contratação $e$ 
dispensa de professores; $V$ - planos de carreira docente".

A lei anterior (Lei $\mathrm{n}^{\mathrm{0}}$ 5.540/68 - Art. $\left.3^{\circ}\right)$ tratava do assunto de forma bastante sucinta ao estabelecer que as universidades gozariam de autonomia didático-científica, disciplinar, administrativa e financeira, exercida na forma da lei e dos estatutos, ficando para a jurisprudência e a doutrina a responsabilidade da conceituação. Neste particular, como já foi dito, a própria Constituição Federal, através do Art. 207, tratou do assunto com bastante clareza.

Por outro lado, parece importante ressaltar, que resta ainda hoje alguma dúvida sobre o que seria considerado como sede da universidade, conceito relevante para o exercício da autonomia no que diz respeito à criação de cursos, uma vez que a lei limita a autoridade à sede da universidade.

Por outro lado, um grande avanço que merece registro é que os estatutos e regimentos das universidades não dependem mais de aprovação pela Câmara de Educação Superior do Conselho Nacional de Educação, dispondo assim as instituições de maior liberdade para elaboração e reforma, respeitada a lei, é evidente.

Os demais artigos, a partir do 54 até o final do capítulo, tratam das universidades mantidas pelo poder público, excetuandose o que parece ser uma possibilidade de extensão da autonomia, que vem no parágrafo segundo do Art. 54, onde é possível o entendimento de que às outras instituições de ensino superior poderá ser dada, dependendo de avaliação do Poder Público, a mesma autonomia das universidades, após comprovação de alta qualificação para o ensino ou para a pesquisa, beneficiando os centros de educação superior, os centros integrados e as faculdades integradas.

O Governo Federal sob a argumentação falaciosa de proteção e defesa dos direitos dos cidadãos, vem reeditando sistematicamente a Medida Provisória que define os valores das mensalidades escolares e as condições contratuais do ensino pré-escolar, fundamental, médio e superior, numa clara interferência na atividade de iniciativa privada.

\section{CONSIDERAÇÕES FINAIS}

Parece evidente o paradoxo dos dias atuais. Multiplicam-se as oportunidades de negócios, ao mesmo tempo em que se multiplicam as concorrentes para o mesmo negócio.

Com o processo de globalização, mercados tradicionais têm mudado com velocidade impressionante. A cada instante são requeridas novas competências. $\mathrm{O}$ consumidor, exercendo grande pressão nas empresas, exige maior qualidade e menor preço de produtos e serviços.

Não se pode negar que as organizações existem dentro de um meio ambiente composto por outras organizações que formam a sociedade, fazendo com que passem a depender umas das outras e da própria sociedade para garantia de sua sobrevivência, indicando assim que as condições nas quais estão envoltas determinam oportunidades e impõem desafios.

Há de se considerar também a vastidão do ambiente e a impossibilidade de sua compreensão por inteiro, além do que sua percepção é levada a efeito pelas pessoas e 
não pela organização, implicando na necessidade de um mapeamento ambiental e uma posterior seleção de variáveis. Essa seleção vai variar de organização para organização, dependendo da interpretação ao estímulo ambiental, traduzindo em síntese a percepção do analista.

Parece que a eficácia de uma organização dependerá, fundamentalmente, de sua capacidade de identificar as oportunidades e necessidades desse ambiente, bem como, de sua flexibilidade e adaptabilidade, objetivando usufruir dessas oportunidades e atender às necessidades identificadas. Supõe-se que o maior desafio é transformar a adversidade (quando for o caso) em vantagem competitiva, o que pode representar toda uma transformação na vida da organização.

É possível, portanto, afirmar que o próprio ambiente fornece as condicionantes básicas de perpetuação ou desaparecimento de uma organização, dependendo, parece evidente, de como ela (organização) percebe $\mathrm{o}$ ambiente e de como se organiza internamente para o enfrentamento da mudança.

As organizações precisam conhecer a si próprias, compreender o ambiente no qual estão inseridas, para, a partir desse entendimento, encetarem medidas que visem a anulação do efeito negativo da mutação do ambiente ou seu aproveitamento enquanto oportunidade, como alavanca para o desenvolvimento.

Sabe-se que as intervenções do Governo Federal sempre afetam o mercado, sendo que em determinadas situações, suas ações têm a magnitude de se infiltrar tanto, a ponto de chegar a afetar posições competitivas firmes dentro de um setor.
Parece, então, que a orientação dominante é que aquelas organizações que estão do lado certo das medidas governamentais devem aproveitar a oportunidade, explorando a posição, para construir ou reforçar sua vantagem em relação às organizações competidoras que não podem.

O Brasil é um dos países onde o Governo exerce maior interferência no ambiente dos negócios e as instituições de ensino superior, como organizações partícipes da composição ambiental, não se constituem em exceção às regras. Ao contrário, fazem coro e ombreiam com as demais organizações.

Constituindo-se em organizações prestadoras de serviços educacionais, as instituições de ensino superior também são sensíveis às regras atuais e suas constantes mutações dependem, cada dia mais, dos resultados obtidos no seu processo de produção, da forma em que se apresentam à comunidade e da forma pela qual são percebidas, como condicionantes de sucesso.

Nas instituições privadas de ensino superior, a influência do governo parece ser mais evidenciada, quando são observados aspectos comuns às demais organizações privadas, mormente aqueles de maior relevância, dentre os quais é possível selecionar o financiamento de suas atividades e seus custos, a tecnologia, a clientela e a concorrência.

Veja-se que o Artigo 209 da Carta Magna promulgada em 5 de outubro de 1988, combinado com o Artigo $7^{0}$ da Lei no 9.394 de 20 de dezembro de 1996, ao estabelecerem que o ensino é livre à 
iniciativa privada, desmoronaram quaisquer tentativas de entendimento de que o ensino privado é uma concessão de direitos. Há em verdade, um empreendimento da iniciativa privada, com capital privado e com todas as conseqüências de um negócio como outro qualquer, respeitando evidentemente as peculiaridades e proporções que lhes são próprias.

Note-se ainda que aquele Artigo $7^{\circ}$ da Lei no 9.394/96, em seu Inciso III, vai além e estabelece como condição precípua para empreender na atividade de ensino, a capacidade de autofinanciamento da iniciativa privada.

Ora, capacidade de autofinanciamento, em atividade de prestação de serviços continuada, requer inegavelmente resultados financeiros positivos da atividade produtiva, o contrário disso não é autofinanciamento. Parece que a realidade não permite que prospere outro entendimento, senão o que estabelece que, necessariamente, deverá existir uma diferença a mais entre a receita e a despesa para que haja continuidade da atividade. Isso em verdade é superávit e, superávit pressupõe lucro.

Por outro lado, a mesma Lei de Diretrizes e Bases da Educação Nacional - LDB (Lei no 9.394/96), criou um novo modo de operar das organizações de ensino superior e o Ministério da Educação - MEC, através das ferramentas legais de que dispõe (Portarias, Resoluções e Pareceres), estabelece procedimentos que visam a operacionalização dos dispositivos da citada Lei, além de criar outros tantos no âmbito de sua competência, principalmente, no que respeita ao desempenho individual das instituições de ensino superior. Além de tudo, o MEC também atua como órgão fiscalizador do cumprimento das normas estabelecidas.

Além dos ditames relativos ao ensino, existem os demais ordenamentos legais a que se submetem as instituições de ensino superior privadas, tais como o Código de Defesa do Consumidor, as Leis Previdenciárias e Trabalhistas, as Leis Cíveis, Comerciais e Tributárias.

Assim, a atividade de prestação de serviços educacionais deve respeito, por um lado, às determinações legais específicas e, por outro, ao que estabelece a norma genérica aplicável, submetendo-se aos órgãos de fiscalização do Governo, tanto no primeiro quanto no segundo ordenamento legal, devendo, além de tudo, ser economicamente viável, para que atenda às exigências de autofinanciamento.

\section{REFERÊNCIAS BIBLIOGRÁFICAS}

BRASIL. Senado Federal. Constituição da República Federativa do Brasil.. Brasília, DF : SF, 1988. . Lei n. ${ }^{\circ}$ 9394, de 20 de dez. 1996, estabelece as Diretrizes e Bases da Educação Nacional. Diário Oficial da União. Ano CXXXIV, $\mathrm{n}^{\circ} 248,23$ de dez. 1996.

CAMARA DOS DEPUTADOS. Lei de Diretrizes e Bases da Educação Nacional. Comentários e sugestões ao projeto lei $n^{o}$ 1258/88. Deputado Jorge Hage. Brasília, 13 de maio de 1989.

CUNHA, Luiz Antônio. A universidade crítica: o ensino superior na República 
Populista. Rio de Janeiro: Francisco Alves, 1989.

MOTTA, Elias de Oliveira, Direito educacional e educação no século XXI: com comentários à nova lei de diretrizes e bases da educação nacional. Brasília: UNESCO, 1997.

NISKIER, Arnaldo. Educação brasileira : 500 anos de história: 1500-2000. Rio de Janeiro: Consultor, 1995.

. LDB : a nova lei da educação: tudo sobre a lei de diretrizes e bases da educação nacional: uma visão crítica. Rio de Janeiro: Consultor, 1996.

UNIÃO NACIONAL DOS ESTUDANTES. Resoluções do conselho da UNE. Rio de Janeiro : Editora Universitária/UNE, 1962.

VASCONCELLOS, José de. Lei de diretrizes $e$ bases da educação nacional. Rio de Janeiro: AEC do Brasil, 1968. 